\title{
1 Changing storminess and global capture fisheries
}

2 Climate change-driven alterations in storminess pose a significant threat to global capture

3 fisheries. Understanding how storms interact with fishery social-ecological systems can

4 inform adaptive action and help to reduce the vulnerability of those dependent on fisheries

5 for life and livelihood.

6 Nigel C. Sainsbury*, Environment and Sustainability Institute, College of Life and

7 Environmental Sciences, University of Exeter, Treliever Road, Penryn, TR10 9FE, UK.

8 ns429@exeter.ac.uk.

9 Martin J. Genner, School of Biological Sciences, University of Bristol, Life Sciences

10 Building, 24 Tyndall Avenue, Bristol BS8 1TQ, UK. M.Genner@bristol.ac.uk.

11 Geoffrey R. Saville, Willis Research Network, Willis Towers Watson, The Willis Building, 51

12 Lime St, London EC3M 7DQ, UK. Geoffrey.Saville@WillisTowersWatson.com. John K. Pinnegar, Centre for Environment, Fisheries and Aquaculture Science, Pakefield Rd, Lowestoft NR33 0HT, UK. John.Pinnegar@cefas.co.uk.

Clare K. O’Neill, Met Office, Fitzroy Rd, Exeter EX1 3PB, UK.

Clare.Oneill@metoffice.gov.uk.

Stephen D. Simpson, Biosciences, College of Life and Environmental Sciences, Geoffrey Pope Building, University of Exeter, Stocker Road, Exeter, EX4 4QD, UK.

S.Simpson@exeter.ac.uk.

Rachel A. Turner, Environment and Sustainability Institute, College of Life and 
Climate change-driven alterations in storminess pose a significant threat to global capture fisheries. Understanding how storms interact with fishery social-ecological systems can inform adaptive action and help to reduce the vulnerability of those dependent on fisheries for life and livelihood.

Fisheries are an important source of food, nutrition, livelihoods and cultural identity on a global scale. Fish provide 3.1 billion people with close to $20 \%$ of their animal protein ${ }^{1}$, and

In addition to ocean warming and acidification, changing storminess is a climate stressor that are relied upon for vital micronutrients, which are particularly critical to the health of children and pregnant women ${ }^{2}$. Capture fisheries and aquaculture are estimated to support the livelihoods of $12 \%$ of the global population and 38 million fishers regularly risk their lives in one of the most dangerous jobs on Earth ${ }^{1}$. Despite its dangers, fishing is an important source of cultural identity and well-being for fishing communities around the world ${ }^{3}$. affects marine life and habitats (Fig. 1a), with potential negative consequences for fish catch and the well-being of coastal communities. Changing storminess also poses a direct risk to fisheries: storms disrupt fishing effort and pose a physical threat to fishers, their vessels and gear, as well as to fishing communities and their infrastructure. Although ocean warming may alter the potential fish catch over the next 50 to 100 years ${ }^{4}$, changing storminess has the potential to cause more immediate and catastrophic impacts. The twenty-first century has already witnessed many tropical, extra-tropical and thunder storms that have claimed thousands of fishers' lives, destroyed fishery-dependent livelihoods and assets, and disrupted the production of commercial inland and marine capture fisheries (Fig. 1b).

The number of storminess reanalysis and projection studies is growing, as is their geographic scope (Fig. 2). However, uncertainty in past and future storminess from global and regional climate models remains high as a result of widespread variation in analytical 
methods, poor historic observational data ${ }^{5}$ and the challenge of distinguishing externally forced climate changes from natural internal climate variability ${ }^{6}$. The attribution of particular extreme weather events to anthropogenic climate forcing is challenging - particularly for storms ${ }^{7}$. Thus, extreme weather event attribution is an expanding area of research and examples for storm events are beginning to emerge ${ }^{8}$.

Despite the difficulties in modelling the location, frequency and intensity of storms, there is sufficient certainty for the IPCC to conclude for the North Atlantic basin (where fisheries productivity is high and historic storm data is particularly rich) that the frequency of the most intense tropical storms has increased since the $1970 \mathrm{~s}^{5}$. A recent review of future winter storminess studies in Europe, ranging over periods spanning 2020-2190, predicts increases in storm frequency and intensity in Western and Central Europe, and decreasing storminess over the North Atlantic north of $60^{\circ} \mathrm{N}$ and in Southern Europe ${ }^{9}$. Evidence of changing storminess from studies outside the North Atlantic includes a northward shift in Western North Pacific tropical cyclone exposure towards the East China Sea ${ }^{10}$ and increased postMonsoon storminess in the Arabian Sea ${ }^{8}$. However, substantial uncertainties in storminess projections remain, and represent a real barrier to effective assessment of global fishery vulnerability.

The uncertainties surrounding the changing nature of storm hazards is paralleled by a lack of knowledge about how storm events directly interact with social and economic variables to influence the behaviour of fishers. In addition, the impacts of storms on marine ecosystems, and the linkages by which these cause indirect social and economic perturbations to fisheries, are little understood. An interdisciplinary research effort is now required to clarify the climatic, social and ecological dimensions of changing storminess to support the assessment of fishery vulnerability and inform adaptive action. 
We advocate a roadmap that draws on climate science, environmental social science, psychology, economics, and ecology, and is based on four interlinked research areas (Fig. 3): (1) developing climate modelling to better understand changing storm hazards; (2) understanding fishers' behavioural response to storms; (3) examining the effects of storms on coastal marine ecosystems and socio-economic linkages; and, (4) assessing fisheries vulnerability and adaptation strategies for changing storminess.

\section{Modelling changing storm frequency and severity}

Identifying the risk to fisheries of changes in storminess requires climate models that provide a reliable spatial and temporal view of past and future frequency and intensity of tropical, extra-tropical and thunder storms. To achieve this, improvements are required in the explicit representation of the sub-grid scale physical processes by which the most intense storms form and develop, such as convection. Advances in ocean-atmosphere coupled models are also necessary to capture the boundary layer processes that drive storms. Progress is being made in these areas, for instance in developing climate models that better represent the coupled ocean-atmosphere processes in tropical cyclones ${ }^{11}$.

Improving the characterization of storms in climate models demands finer spatial resolution and a shortening of time steps, which will intensify the trade-off between resolution and timescale of simulations that results from limited computing resources. Supported by greater computing power, enhanced representation of storms in climate models will improve both reanalysis and predictions of storminess and strengthen our understanding of the influence of climate variability at seasonal to decadal timeframes on storm events.

\section{Fishers' behavioural response to storms}

The effect of storms on fisheries is in part a function of fishers' behavioural response to meteorological conditions. The heterogeneity of fisher decisions regarding whether to participate, and where to fish, in adverse weather conditions for different fishery types, 
vessel characteristics and social and cultural contexts around the world should be explored. Fishers' decisions on where and when to fish are known to be affected by a complex array of socio-economic factors ${ }^{12}$. However, the way in which fishers make weather-related decisions is poorly understood. We do not know how projected weather information is used or if it accessible to fishers. It will be important to understand fisher decisions to go to sea, or stay at sea, during storms, how weather conditions affect the distribution of fishing activity, the performance of different gears in adverse weather and the interaction of perceptions of physical and economic risk in decision-making.

Explaining the behavioural response of fishers to storms will require the involvement of psychologists, sociologists, anthropologists and economists employing research methods across the epistemological spectrum. Qualitative approaches can unravel the complexity of factors, motivations and processes underpinning decision-making, whereas experimental methods, such as economic choice experiments, offer the potential to reveal how decisions are made where observational data are not readily available, as is the case in many tropical fisheries. The increasing availability of on-board satellite vessel tracking technology and wind and wave hindcast modelled data is creating the potential to model the behavioural response of fishers to weather conditions at unprecedented temporal and spatial resolutions. In addition, the emerging application of agent-based modelling approaches to fisheries could reveal the weather-related behaviour of fleets based on the decisions and interactions of individual fishers.

\section{Coastal marine ecosystems and socio-economic linkages}

Storms have the capacity to cause extensive disturbance to marine ecosystems and habitats that support productive fisheries. Several areas require investigation to improve our knowledge: little is known about the manner in which fish lifecycle events (including spawning migrations, larval growth and dispersal during the planktonic larval phase) and the use of shallow nursery ground habitats, are influenced by storm disturbance. There is some 
evidence that fish may evacuate storm areas or be redistributed by storm waves and currents (Fig. 1a), but this requires further exploration. Storm-induced fish mortality events, such as the death of 400,000 fish in the Nyanza Gulf of Lake Victoria following post-storm deoxygenation and turbidity in $1984^{13}$, are poorly understood. Finally, the way that changing storminess interacts with other marine impacts of climate change (such as ocean warming, acidification and deoxygenation) to affect marine ecosystems remains unexplored.

Interdisciplinary efforts are required to uncover how direct marine ecosystem impacts are linked with indirect social and economic impacts on fisheries. Although there are examples of storm damage to key habitats, we know little of how this consequently influences the abundance or catchability of targeted fish species. We lack knowledge of how storm-induced changes in fish distribution affect fishery catches, but fishers' logbooks may offer a rich source of data to address this gap.

\section{Vulnerability and adaptation strategies}

Assessing the vulnerability of fisheries to changing storminess is essential for prioritizing limited adaptation resources and informing adaptation strategies. The exposure of fisheries will vary spatially with projected changes in storm risk, target fish species, the resilience of infrastructure and the extent of natural and man-made storm defences. It is probable that the impact of changing storminess on fisheries will be socially differentiated, with severe impacts more likely to affect small-scale fisheries. The vulnerability of fisheries to changes in storminess is unclear at present. Fishery vulnerability assessments developed over the past decade have acknowledged, but not reflected, changing storminess ${ }^{14}$, largely because of the gaps in knowledge outlined here. These assessments can be enhanced by incorporating appropriate measures of exposure, sensitivity and adaptive capacity to storms.

Fishery adaptation measures will require evaluation in local contexts. Possibilities include technological advances, improvements in the accuracy and communication of weather forecasts, and innovative financial solutions. In Kerala, India, a weather forecast service 
called Radio Monsoon (https://twitter.com/radiomonsoon) provides daily information over loudspeaker in harbours and through social media. Insurance schemes triggered by environmental indexes are growing in popularity in terrestrial agriculture ${ }^{15}$ and could increase the resilience of fisheries to increased storminess. Modifications of this concept would have to reflect the nature of daily harvesting activity and the dynamic nature of marine resources. Some fishers may also have opportunities to adapt to take advantage of reduced storminess, which may exacerbate existing challenges to sustainable natural resource use.

\section{Conclusion}

Greater attention to the research priorities outlined here could help inform adaptation and protect the well-being of billions of people worldwide. Although scientists are actively working in some of these areas, research gaps remain, and existing knowledge is yet to be applied to this social-ecological climate issue. The potentially catastrophic impacts of changing storminess for global fisheries across relatively short timescales mean that enhanced integration across disciplines is urgently needed to address this challenge.

\section{Acknowledgements}

N.C.S. acknowledges the financial support of the UK Natural Environment Research Council (NERC; GW4+ studentship NE/L002434/1), Centre for Environment, Fisheries and Aquaculture Science and Willis Research Network. We thank Emma M. Wood, who provided design services for the figures.

\section{Competing Interests statement}

J.K.P. is a co-chair of the "ICES-PICES Strategic Initiative on Climate Change Impacts on Marine Ecosystems" and will be a Lead Author for the "Small Islands" chapter within the IPCC 6th Assessment Report (AR6 - WGII).

\section{References}

1. FAO. The State of World Fisheries and Aquaculture (Rome, 2016). 
2. Golden, C.D. et al. Nature 534, 317-320 (2016).

3. Coulthard, S., Johnson, D. and McGregor, J.A. Glob. Environ. Change 21, 453-463 (2011).

4. Cheung, W.W.L. et al. Glob. Change Biol. 16, 24-35 (2010).

5. Hartmann, D.L. et al. Observations: Atmosphere and Surface. In: Climate Change 2013: The Physical Science Basis (eds. Stocker, T. F. et al.) (Cambridge Univ. Press, 2013).

6. Bindoff, N. L. et al. in Climate Change 2013: The Physical Science Basis (eds Stocker, T. F. et al.) Ch. 10 (IPCC, Cambridge Univ. Press, 2013).

7. Trenberth, K.E., Fasullo, J.T. and Shepherd, T.G. Nat. Clim. Change 5, 725-730 (2015).

8. Murakami, H., Vecchi, G.A. and Underwood, S. Nat. Clim. Change 7, 885-889 (2017).

9. Mölter, T., Schindler, D., Albrecht, A.T. and Kohnle, U. Atmosphere-Basel 7, 60 (2016).

10. Kossin, J.P., Emanuel, K.A. and Camargo, S.J. J. Clim. 29, 5725-5739 (2016).

11. Scoccimarro, E. et al. J. Clim. 30, 145-162 (2017).

12. van Putten, I.E. et al. Fish Fish. 13, 216-235 (2012).

13. Ochumba, P.B.. Hydrobiologia 208, 93-99 (1990).

14. Allison, E.H. et al. Fish Fish. 10, 173-196 (2009).

15. Surminski, S., Bouwer, L.M. and Linnerooth-Bayer, J. Nat. Clim. Change 6, 333-334 (2016).

201

202

203

204

205

206

207

208 
a

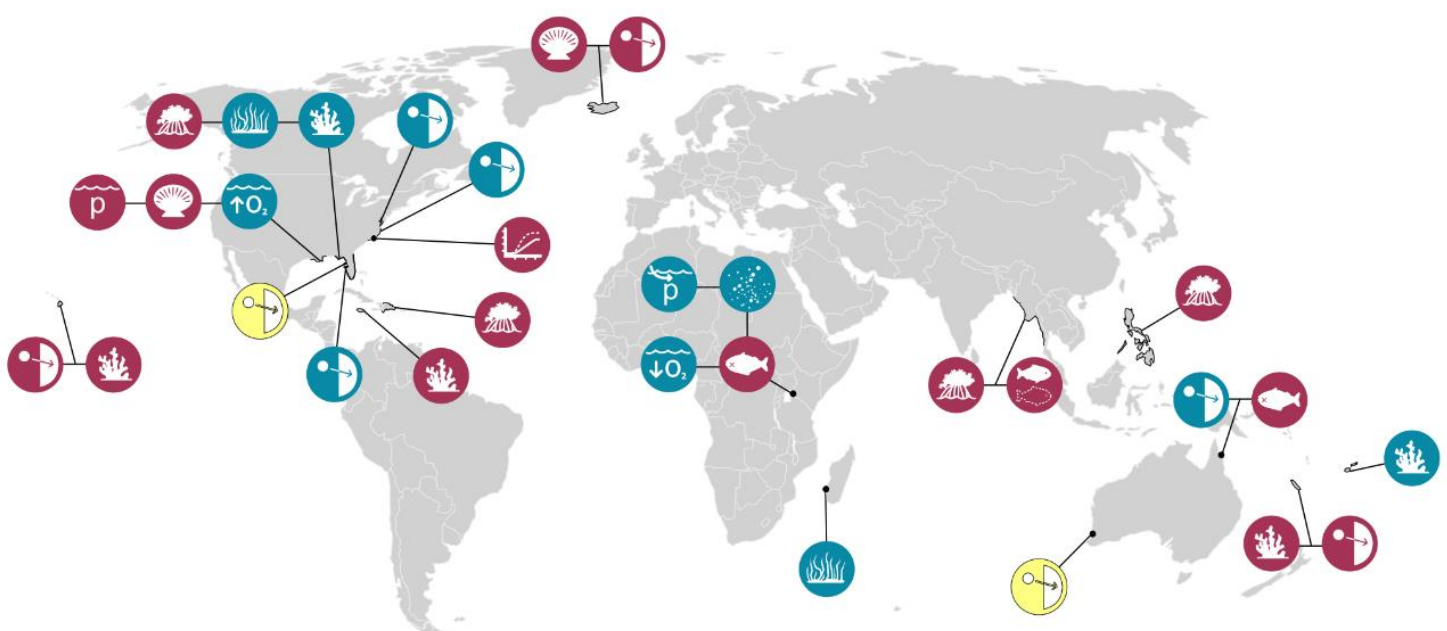

KEY

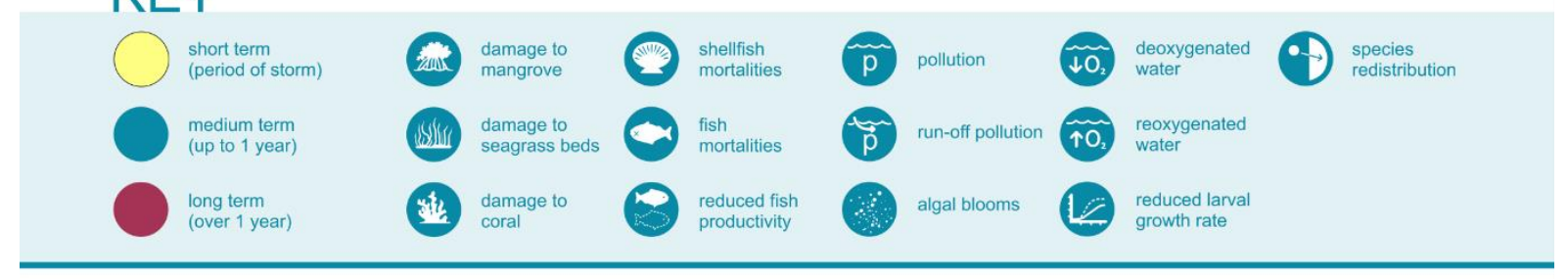

b

\section{KEY}

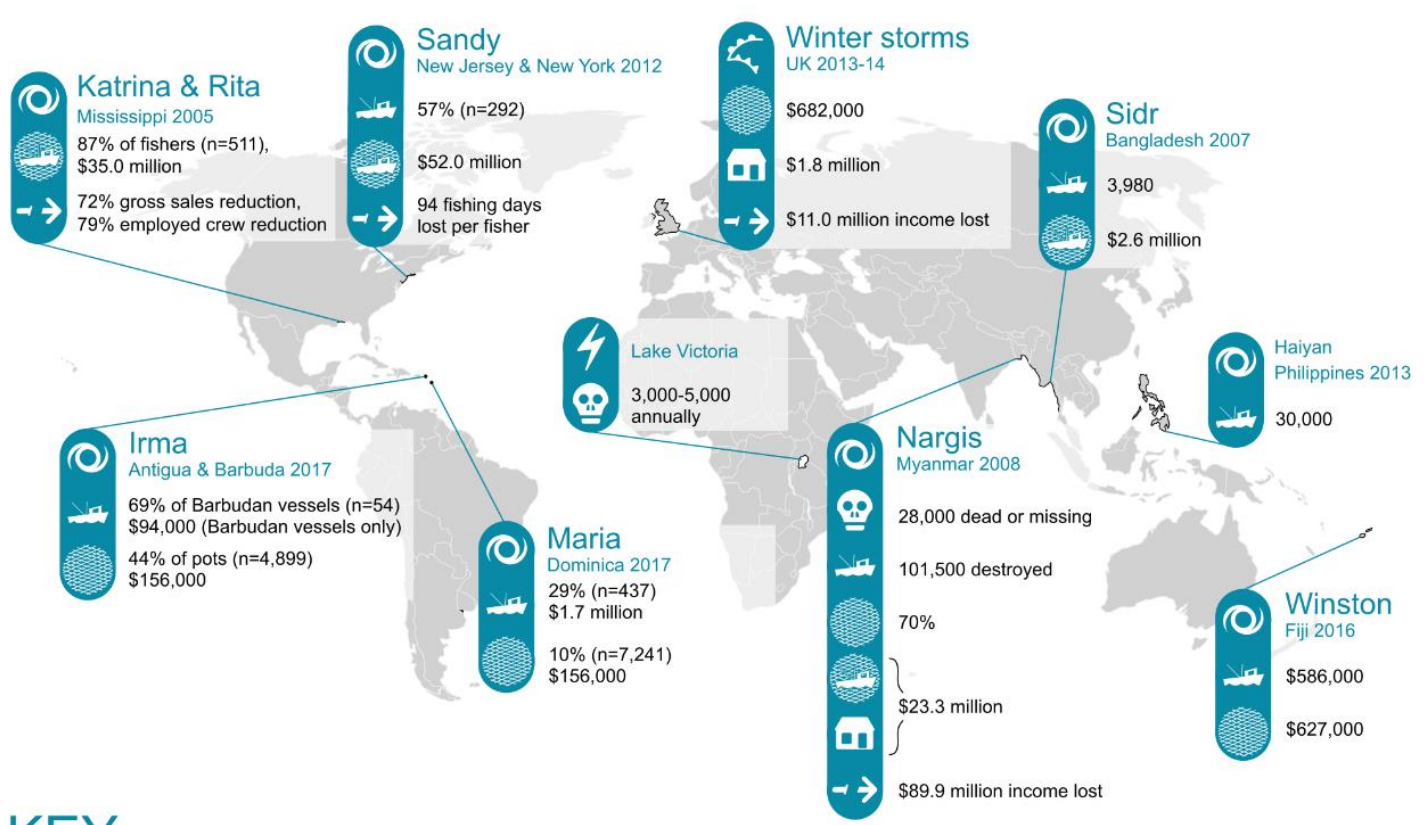

vessels damaged,
destroyed, or lost
gear damaged,
destroyed, or lost
$\begin{aligned} & \text { vessels \& gear damaged, } \\ & \text { destroyed, or lost }\end{aligned}$

211 Figure 1. Ecological, social and economic impacts of storms on fisheries. (a)

212 Examples of storm-induced marine ecosystem disturbances. For further detail see 

case studies from the twenty-first century. Case studies were selected based on scale of the impacts, global geographic spread and availability of data. For further detail see Supplementary Information Section $\mathbf{1 b}$.

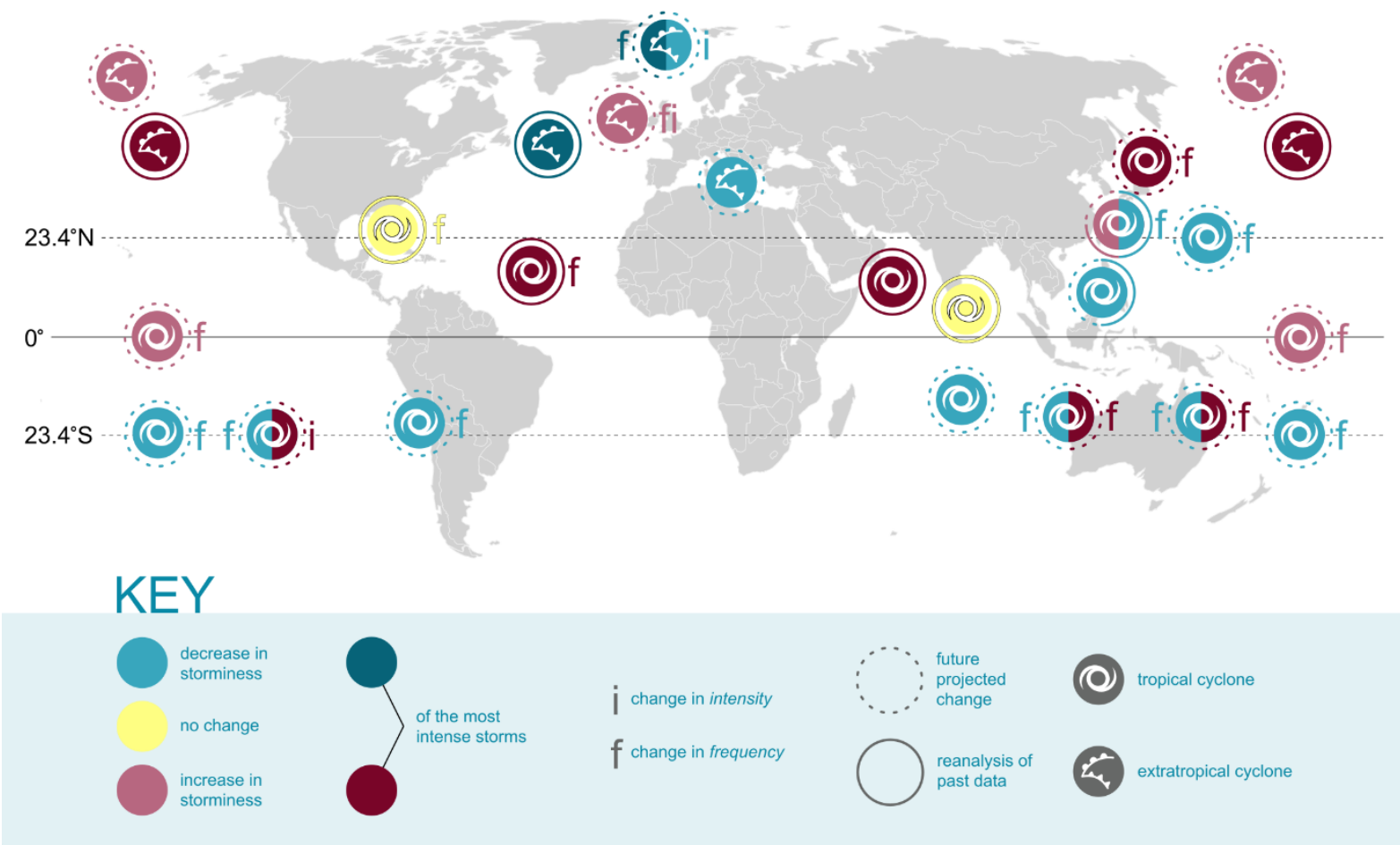

Figure 2. The spatially heterogeneous nature of changing global storminess. The selection of studies is not systematic, but is designed to reflect a range of studies carried out for the Atlantic, Pacific and Indian Oceans, which account for the majority of global fish catch. For further detail see Supplementary Information Section 2. 


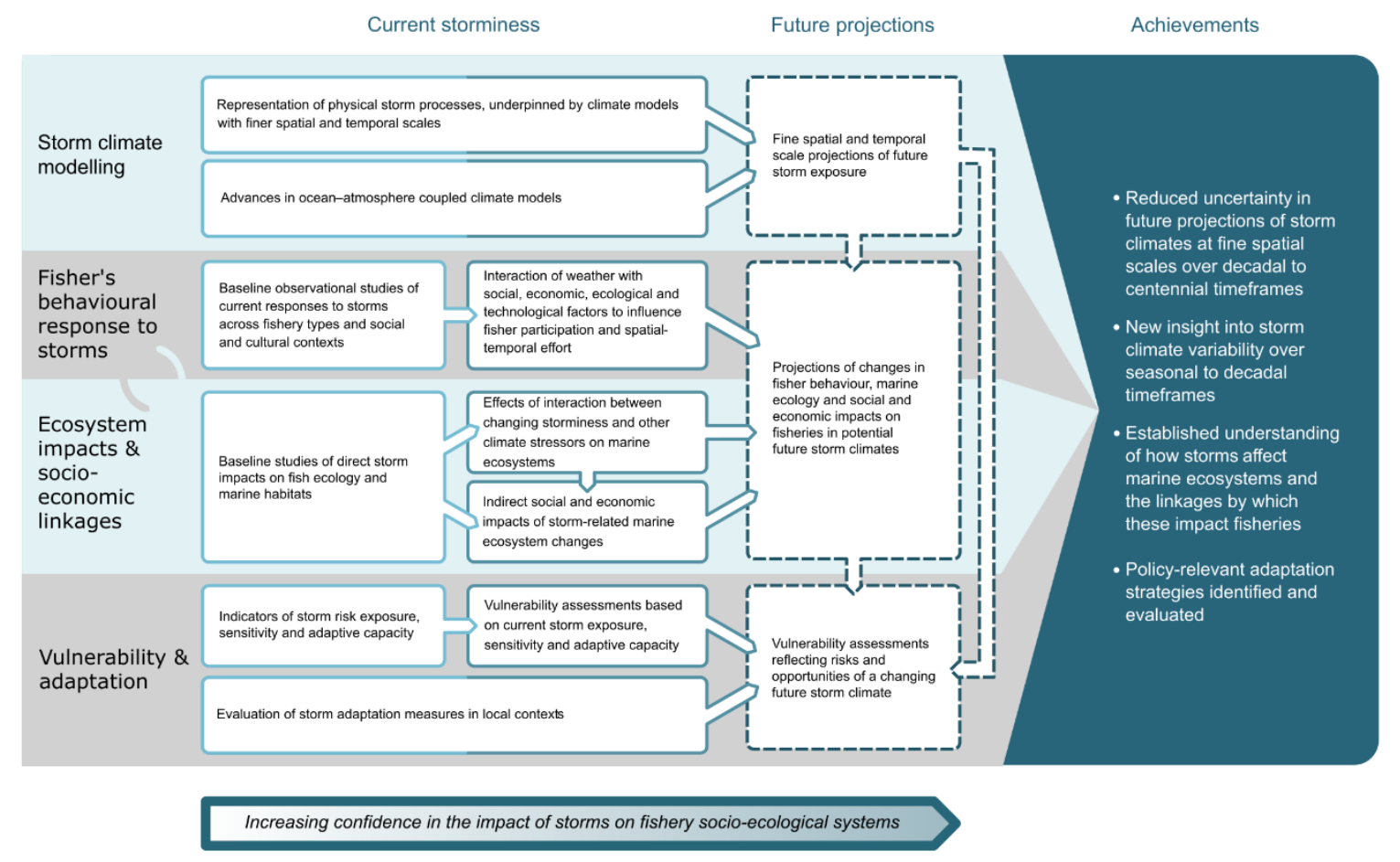

223 Figure 3. Schematic of a research roadmap to understand the impact of changing

224 storminess on fisheries. Straight arrows between boxes demonstrate the

225 dependencies within and between research streams. Curved arrows represent the

226 feedback loop in which changes in fisher behaviour affect the ecosystem and

227 changes to the ecosystem affect fisher behaviour. Collaboration will be required

228 between research streams. The order of research streams does not represent

229 importance or priority. 
236 Changing storminess and global capture fisheries

237 Nigel C. Sainsbury, Martin J. Genner, Geoffrey R. Saville, John K. Pinnegar, Clare K.

238 O'Neill, Stephen D. Simpson, Rachel A. Turner

239 Supplementary Information Section 1a

240 This section provides references and additional detail for Figure 1a.

a

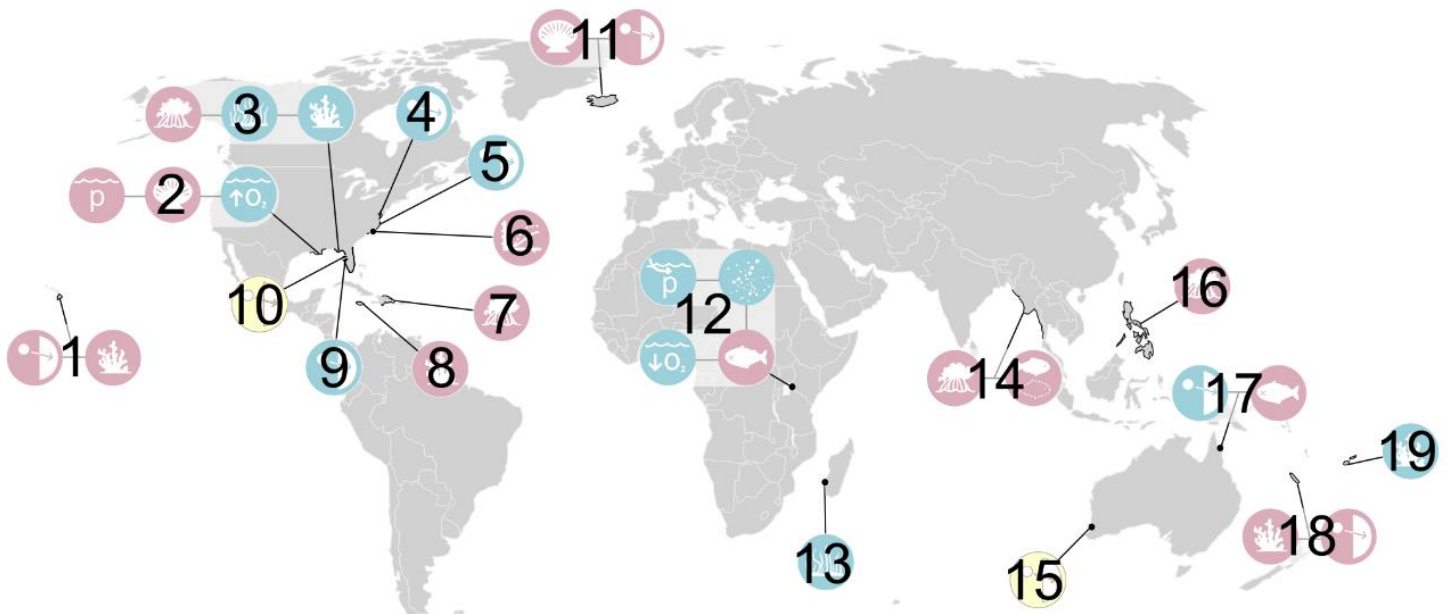

KEY
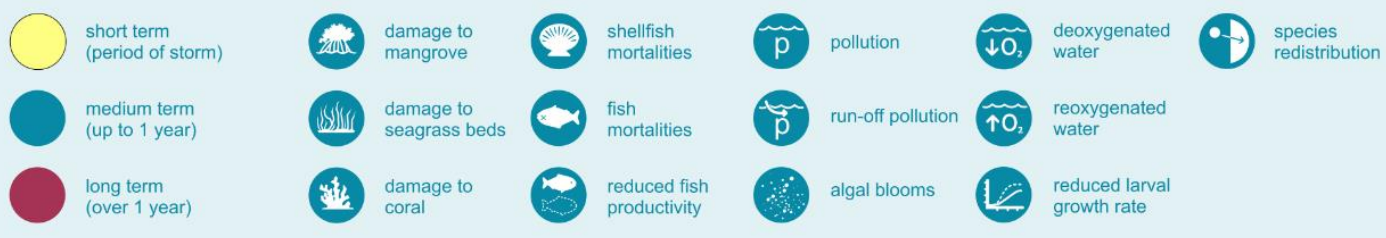

Supplementary Figure 1a. Figure 1a with additional case study reference numbers linking to Supplementary Table $1 a$. 


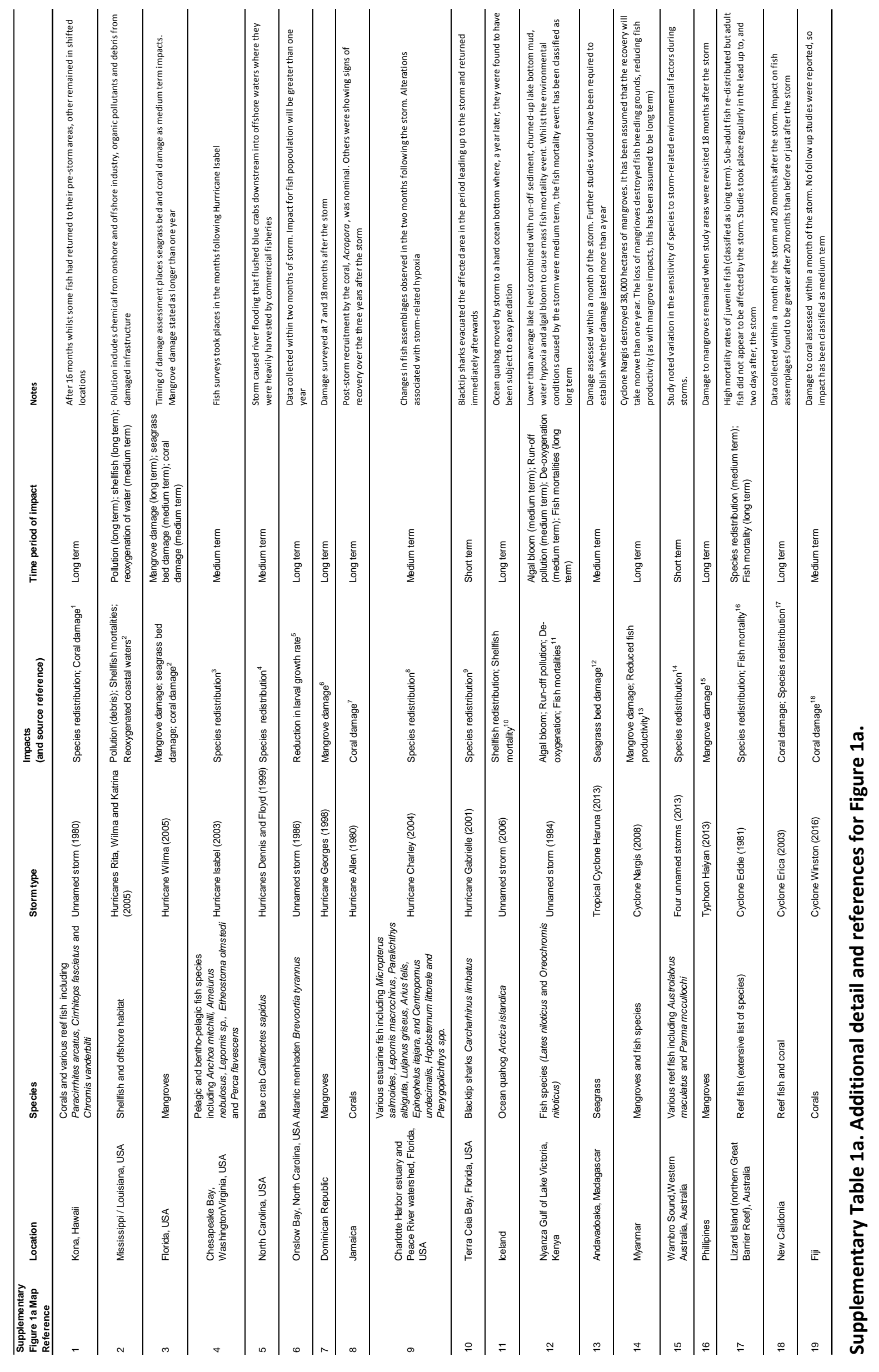


254 This section provides references and additional detail for Figure 1b.

b

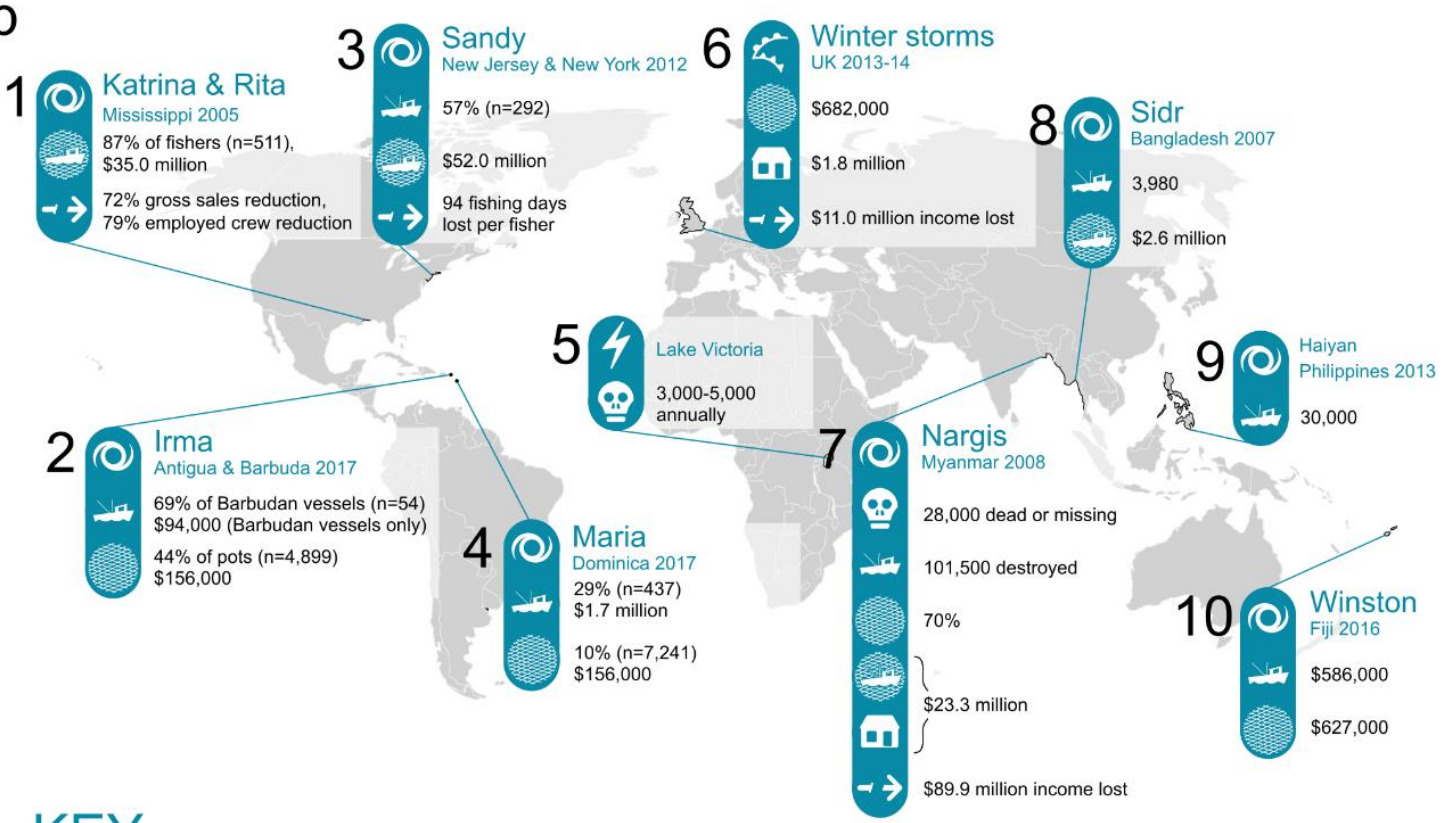

KEY
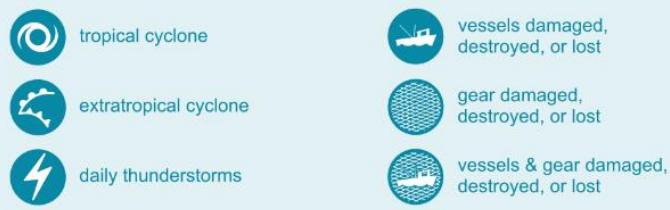

(1) infrastructure damage

$\rightarrow$ fishing disruption

figher/ fishery worker
fatalities

Supplementary Figure $1 \mathrm{~b}$. Figure $1 \mathrm{~b}$ with additional case study reference numbers linking to Supplementary Table $1 \mathrm{~b}$. 


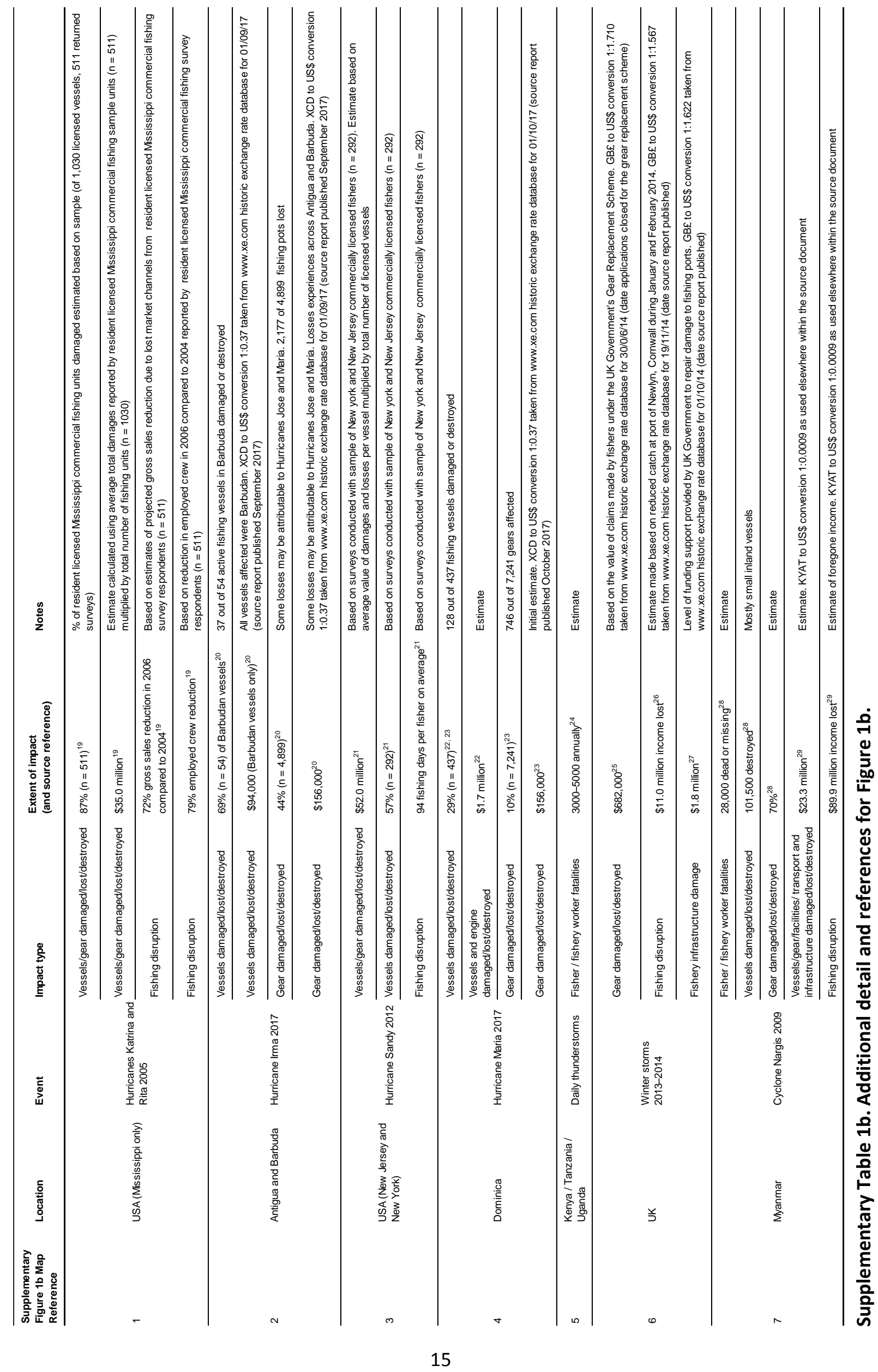




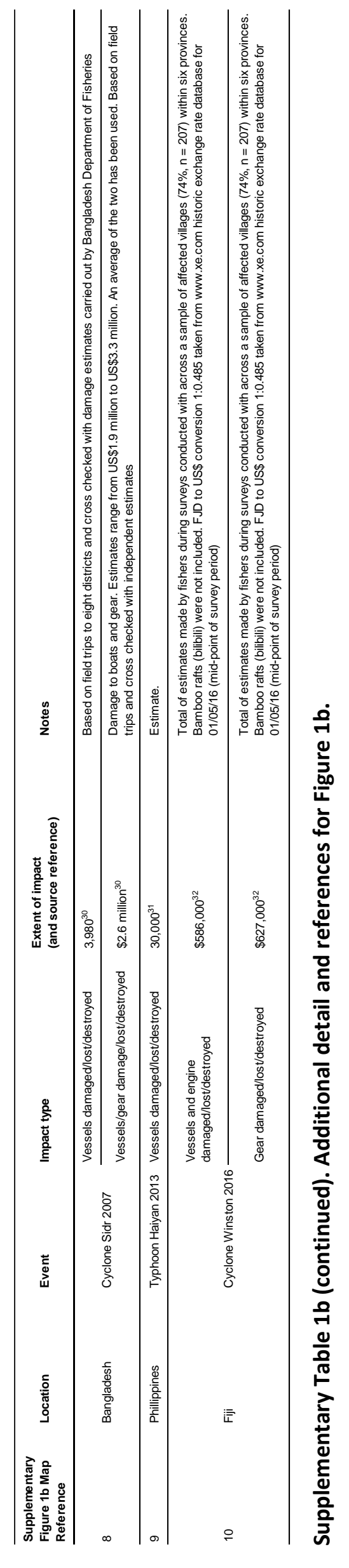


270 This section provides references and additional detail for Figure 2.

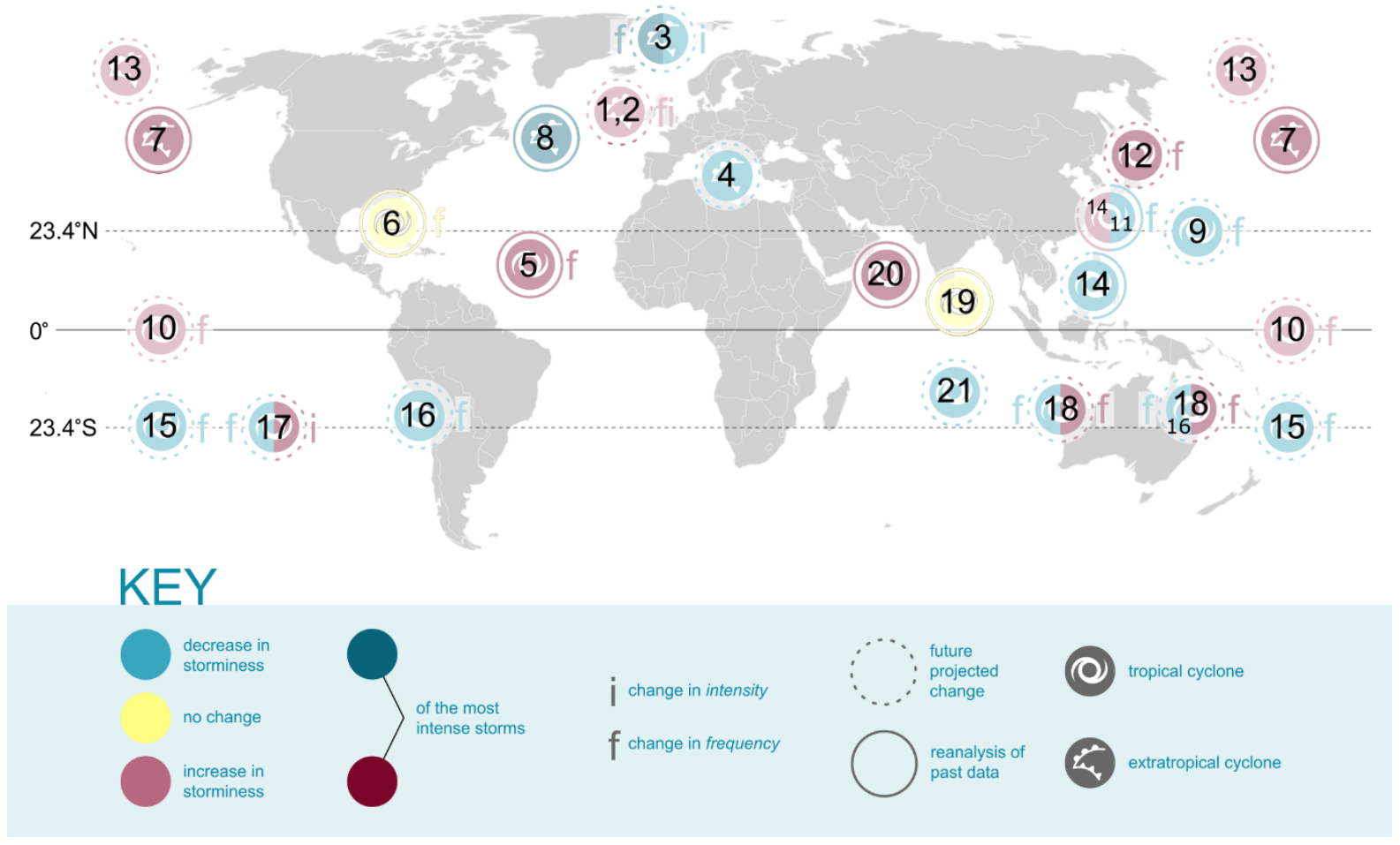

271

272

Supplementary Figure 2. Figure 2 with additional case study reference numbers 


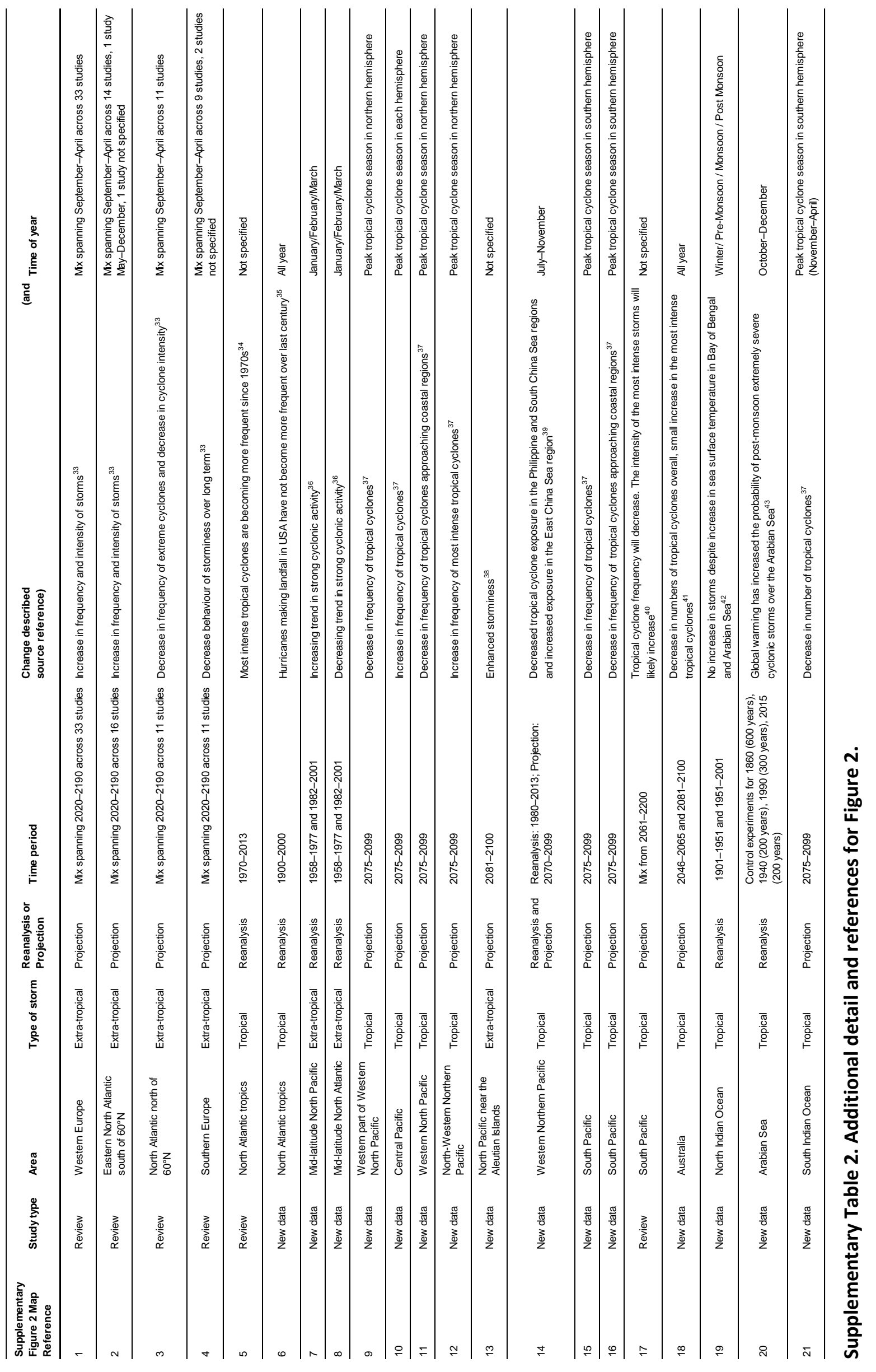


16. Walsh, W.J., Coral Reefs 2, 49-63 (1983).

17. U.S. Department of Commerce, National Oceanic and Atmospheric Administration, National Marine Fisheries Service. Report to Congress on the Impact of Hurricanes Katrina, Rita, and Wilma on Commercial and Recreational Fishery Habitat of Alabama, Florida, Louisiana, Mississippi, and Texas (Maryland, 2007).

18. Houde, E.D., Bichy, J. and Jung, S. K.G. Effects of Hurricane Isabel on Fish Populations and Communities in Chesapeake Bay. In: Hurricane Isabel In Perspective (ed. Sellner, K.G.). pp. 193-199 (Maryland, 2005).

19. Burgess, C., Bianchi, A., Murauskas, J. and Crosson, S. Impacts of Hurricanes on North Carolina Fisheries (North Carolina, 2007).

20. Maillet, G.L. and Checkley, Jr, D.M. Mar. Ecol. Prog. Ser. 79, 1-16 (1991).

21. Sherman, R.E., Fahey, T.J. and Martinez, P. Biotropica 33, 393-408 (2001).

22. Hughes, T.P., Science 265, 1547-1551 (1994).

23. Stevens, P.W., Blewett, D.A. and Casey, J.P. Estuar. Coast 29, 997-1003 (2006).

24. Heupel, M.R., Simpfendorfer, C.A. and Hueter, R.E. J. Fish Bio. 63, 1357-1363 (2003).

25. Thórarindsóttir, G.G., Gunnarsson, K. and Bogason, E. Mar. Biodivers. Rec. 2 (2009).

26. Ochumba, P.B. Hydrobiologia 208, 93-99 (1990).

27. Côté-Laurin, M.C., Benbow, S. and Erzini, K. Cont. Shelf Res. 138, 132-141 (2017).

28. United Nations Environment Programme. Learning from Cyclone Nargis. (Nairobi, 2009).

29. Munks, L.S., Harvey, E.S. and Saunders, B.J. J. Exp. Mar. Biol. Ecol. 472, 77-88 (2015).

30. Long, J., Giri, C., Primavera, J. and Trivedi, M. Mar. Pollut. Bull. 109, 734-743 (2016).

31. Lassig, B.R., Environ. Biol.Fish. 9, 55-63 (1983).

32. Wantiez, L., Chateau, O. and Le Mouellic, S. J. Mar. Biol. Assoc. U.K. 86, 1229-1236 (2006). 
33. Mangubhai, S. Impact of Tropical Cyclone Winston on Coral Reefs in the Vatu-i-Ra Seascape. WCS Report No. 01/16 (Fiji, 2016).

34. Posadas, B.C. Mississippi Agricultural and Forestry Experiment Station Bulletin 1165 (Mississippi State, 2008).

35. Horsford, I. Hurricane Irma - Preliminary Damage Assessment for Antigua And Barbuda's Fisheries Sector (Fisheries Division Ministry of Agriculture, Lands, Fisheries and Barbuda Affairs, St John's, 2017).

36. Colburn, L.L., Clay, P.M., Seara, T., Weng, C. and Silva, A. U.S. Dept. of Commerce, NOAA. NOAA Technical Memorandum NMFS-F/SPO-157 (Narragansett, 2015).

37. Government of Commonwealth of Dominica Fisheries Division. Preliminary Damage Assessment for Dominica's Fisheries Sector - Post Hurricane Maria (Roseau, 2017).

38. Government of Commonwealth of Dominica. Post-Disaster Needs Assessment Hurricane Maria September 18, 2017 (Dominica, 2018).

39. International Federation of the Red Cross and Red Crescent Societies. World Disasters Report Focus on culture and risk (2014).

40. UK Marine Management Organisation Media Team, Personal comms., 23 November 2017 and 2 May 2018.

41. Andrew, R. and Read, D. Cumulative Impact of Severe Weather in Cornwall: Winter 2013/2014 (Cornwall Council, 2014).

42. Watkins, D. The winter storms of 2014: How Cornwall fared (Cornwall Council, 2014).

43. FAO. Myanmar Post-Nargis Recovery and Rehabilitation Programme Strategy (Myanmar, 2009)

44. Government of Myanmar, ASEAN and UN. Post-Nargis Joint Assessment (Myanmar, 2008).

45. Government of Bangladash. Cyclone Sidr in Bangladesh Damage, Loss and Needs Assessment For Disaster Recovery and Reconstruction (Bangladesh, 2008).

46. FAO. Typhoon Haiyan - One year later, accessed 30 November 2017, http://www.fao.org/news/story/en/item/264765/icode/ 
47. Chaston Radway, K. et al. Impact of Tropical Cyclone Winston on Fisheries-Dependent Communities in Fiji. WCS Report No. 03/16 (Fiji, 2016).

33. Mölter, T., Schindler, D., Albrecht, A.T. and Kohnle, U. Atmosphere-Base/ 7, 60 (2016)

34. Hartmann, D.L. et al. Observations: Atmosphere and Surface. In: Climate Change 2013: The Physical Science Basis (eds. Stocker, T.F. et al.) (Cambridge Univ. Press, 2013).

35. Landsea, C.W. Bull. Am. Meteorol. Soc. 96, 1175-1176 (2015).

36. Wang, X.L., Swail, V.R. and Zwiers, F.W. J. Clim. 19, 3145-3166 (2006).

37. Murakami, H. et al. J. Clim. 25, 3237-3260 (2012).

38. Ulbrich, U. et al. J. Clim. 21, 1669-1679 (2008).

39. Kossin, J.P., Emanuel, K.A. and Camargo, S.J. J. Clim. 29, 5725-5739 (2016).

40. Walsh, K.J., Mclnnes, K.L. and McBride, J.L. Global Planet. Change 80, 149-164 (2012).

41. Lavender, S.L. and Walsh, K.J.E. Geophys. Res. Lett. 38, 5725-5739 (2011).

42. Ramesh Kumar, M R. and Sankar, S. Indian J. Geo-Mar. Sci. 39, 516-520 (2010).

43. Murakami, H., Vecchi, G.A. and Underwood, S. Nat. Clim. Change 7, 885-889 (2017). 